\title{
PENGASUHAN DAN STIMULASI TUMBUH KEMBANG ANAK MELALUI PELAYANAN TERINTEGRASI TAMAN PENITIPAN ANAK DAN BABY/ KIDS SPA GRIYA SEHAT
}

\author{
(Parenting Accompaniment and Growth-Development Stimulation through \\ Integrated Services Daycare Center and Baby/ Kids SPA Griya Sehat Bayi dan \\ Balita)
}

\section{MADE ERMAYANI, APRILIA NURYANTI, YOVITA ERIN SASTRINI}

Program Studi Diploma III Keperawatan STIKES Dirgahayu Samarinda

JI. Pasundan No.21, Kelurahan Jawa, Kecamatan Samarinda Ulu, Kota Samarinda, Kalimantan Timur Kode Pos 75122

Emai: ermayani.made@gmail.com, aprilnuryanti@gmail.com

\section{Abstract}

Difficulties about parenting for working parents and how to stimulate the growth of children's development are a challenge to the business. Parents who entrust children expect to be well cared for by care for health. Griya Sehat Bayi dan Balita is an effort that provides comprehensive services to the needs of parents to monitor and develop the growth and development of infants or toddlers. The specific target this program is to provide a vehicle for universities to develop the application of technology in the health and nursing of infants / toddlers based on the results of research and community service. The service provided is a child care center with online CCTV service, assessment and stimulation of growth and development of SPA for toodler. Griya Sehat Bayi dan Balita gives job opportunities for alumni and become place of internship for student of STIKES Dirgahayu Samarinda. The daycare unit opened in March with capacity of 10 children with four sitter-in. SPA units operate from May 2018 with a therapist, an admin and four volunteer. The parent's evaluation of daycare in the $80 \%$ is satisfied and $20 \%$ stated very satisfied. Greeting, friendliness, speed of response and completeness of the facility is considered very satisfactory. Clarity type of service, cleanliness and comfort is considered satisfactory by the customer.

Keywords: parenting, growth and development, baby SPA, child care, daycare

\section{Abstrak}

Kesulitan tentang pengasuhan anak bagi orang tua yang bekerja dan cara melakukan stimulasi pertumbuhan perkembangan anak menjadi tantangan usaha. Orang tua yang menitipkan anak berharap di tempat penitipan anak diasuh dengan baik dengan memperhatikan kesehatan. Griya sehat bayi dan balita merupakan usaha yang memberikan pelayanan komprehensif terhadap kebutuhan orang tua untuk memantau dan mengembangkan pertumbuhan dan perkembangan bayi atau balitanya. Target khusus program ini adalah menyediakan wahana bagi perguruan tinggi untuk mengembangkan penerapan teknologi di bidang kesehatan dan keperawatan bayi/ balita berdasarkan hasil penelitian dan pengabdian masyarakat. Pelayanan jasa yang diberikan adalah taman penitipan anak dengan online CCTV service, pemeriksaan dan stimulasi tumbuh kembang serta perawatan SPA balita. Griya sehat memberi peluang pekerjaan bagi alumni dan menjadi tempat magang bagi mahasiswa STIKES Dirgahayu Samarinda. 
Unit TPA dibuka pada bulan Maret dengan daya tampung 10 anak dengan jumlah pengasuh empat orang. Unit SPA beroperasi mulai bulan Mei 2018 dengan jumlah terapis satu orang, admin satu orang dan mahasiswa magang empat orang. Penilaian orang tua terhadap pengasuhan di unit TPA $80 \%$ menyatakan puas dan $20 \%$ menyatakan sangat puas. Penyambutan, keramahan, kecepatan respon dan kelengkapan fasilitas dinilai sangat memuaskan. Kejelasan jenis pelayanan, kebersihan dan kenyamanan dinilai memuaskan oleh pelanggan.

Kata kunci: pengasuhan, tumbuh kembang, baby SPA, penitipan anak, daycare

\section{PENDAHULUAN}

STIKES Dirgahayu Samarinda merupakan institusi perintis pendidikan keperawatan, yang telah berdiri sejak tahun 2000. Tenaga pendidik dan kependidikan STIKES Dirgahayu Samarinda sebagian besar adalah lbu Rumah Tangga (IRT), yang memiliki sedikit kesulitan tentang pengasuhan anak. Sebagian besar pengasuhan anak dilakukan melalui taman penitipan anak (TPA). TPA yang ada mempunyai daya tampung yang sedikit dan hanya memberikan pelayanan penitipan anak saja. Sedangkan kebutuhan orang tua.

untuk memaksimalkan pertumbuhan dan perkembangan buah hatinya sangat banyak ragamnya. Kesulitan tentang pengasuhan anak bagi orang tua yang bekerja juga dikeluhkan oleh pegawai Rumah Sakit Dirgahayu dan pegawai swasta lainnya yang berada di kota Samarinda. Orang tua membutuhkan lebih dari sekedar penitipan anak, dan terutama tentang keamanan dan kenyaman bagi buah hatinya ketika tidak bersama orang tuanya..

Griya sehat bayi dan balita merupakan suatu usaha yang akan memberikan pelayanan berupa jasa yang terkait dengan pengasuhan bayi dan balita, perawatan dan stimulasi pertumbuhan dan perkembangan dengan target konsumen adalah orang tua yang memiliki bayi dan atau balita. Griya sehat bayi dan balita merupakan usaha yang memberikan pelayanan komprehensif terhadap kebutuhan orang tua untuk memantau dan mengembangkan pertumbuhan dan perkembangan bayi atau balita-nya. Pelayanan jasa yang akan diberikan adalah perawatan, pemeriksaan dan stimulasi tumbuh kembang bayi dan balita. Usaha sejenis yang mirip dengan konsep griya sehat bayi dan balita ini adalah usaha TPA dan SPA bayi. Di Samarinda terdapat beberapa usaha TPA dan SPA bayi, tapi hanya berfokus pada penitipan anak saja atau hanya perawatan seperti SPA dan massage pada bayi dan balita. Sedangkan pada konsep griya sehat bayi dan balita akan menggabungkan konsep TPA dan SPA, selain itu juga akan memberikan pelayanan pemeriksaan tumbuh kembang Denver Developmental Screening Test (DDST), pemeriksaan berat badan dan tinggi badan. Denver Developmental Screening Test (DDST) merupakan metode skrining empat aspek tugas perkembangan bayi dan balita yaitu Personal Social (kepribadian atau tingkah laku social), Fine Motor Adaptif (gerakan motorik halus), Language (bahasa) dan Gross Motor (perkembangan motorik kasar) (Wong, 2008).

Lokasi usaha griya sehat bayi dan balita terletak sangat strategis yaitu di Jalan K.S. Tubun yang berdekatan dengan STIKES Dirgahayu Samarinda, Rumah Sakit Dirgahayu, Sekolah Dasar Katolik 1 WR.Soepratman, SMP Katolik 1 WR. Soepratman,

Griya sehat bayi dan balita memberikan kesempatan bagi orang tua yang bekerja untuk mempercayakan perawatan bayi atau balita-nya selama mereka bekerja sehingga wanita sebagai seorang ibu tetap bisa membantu 
kesejahteraan hidup keluarga, tanpa khawatir dengan proses tumbuh kembang anaknya. Orang tua tetap dapat memantau bayi atau balita-nya melalui layanan online CCTV dan whatsapp group yang disediakan oleh griya sehat bayi dan balita. Griya sehat bayi dan balita membantu orang tua untuk menggantikan perannya dalam memberikan kebutuhan dasar anak yaitu kasih sayang, dan stimulasi yang akan berpengaruh terhadap kualitas hidup saat mereka dewasa.

\section{METODOLOGI}

Modal usaha Griya Sehat Bayi dan Balita didapatkan dari dua sumber dana. Sumber dana dan barang inventaris yang berasal dari institusi STIKES Dirgahayu Samarinda dan dana hibah pengabdian kepada masyarakat dari Kemenristek Dikti dengan skema Program Pengembangan Usaha Produk Intelektual Kampus (PPUPIK) dengan Kontrak Pengabdian kepada Masyarakat tahun anggaran 2018 nomor: $580 /$

KONTRAKPENGABDIAN/K11/ KM/ 2018 Tanggal 22 Februari 2018 dengan nilai kontrak Rp. 150.000.000 (Seratus Lima Puluh Ribu Rupiah).

Pengelolaan usaha ini dilakukan oleh tim pengusul dan dibantu oleh dosen STIKES Dirgahayu yang secara teknis mengawasi jalannya usaha yang ditetapkan berdasarkan surat keputusan (SK) Ketua STIKES Dirgahayu Samarinda. Tanggung jawab pelaporan usaha kepada Ketua STIKES Dirgahayu Samarinda, Ketua Yayasan Setia Budi Samarinda dan kepada Kemenristek Dikti selaku pemberi hibah.

Lokasi usaha di jalan K.S. Tubun No. 30B. Tempat usaha dibagi menjadi dua lantai yaitu lantai pertama untuk SPA dan massage pada bayi serta balita, pemeriksaan DDST, pemeriksaan berat badan, tinggi badan dan ruang konsultasi pertumbuhan perkembangan bagi orang tua bayi/ balita. Ruangan lantai satu dilengkapi dengan fasilitas kolam renang untuk bayi, bathtub untuk balita, matras untuk massage, timbangan bayi dan balita, pengukur tinggi badan, dan alat pemeriksaan DDST dengan desain ruangan yang menarik untuk bayi dan balita. Lantai 2 digunakan untuk unit taman penitipan anak (TPA). TPA dilengkapi dengan tempat istirahat, fasilitas bermain yang aman dan sesuai dengan usia bayi/ balita, serta desain

ruangan yang menarik dan menstimulasi perkembangan bayi/ balita serta pemantauan online CCTV yang dapat diakses orang tua selama anak dititipkan. Kapasitas TPA adalah 10 orang anak.

Staf yang bekerja pada Griya Sehat adalah seorang perawat lulusan diploma III Keperawatan yang merupakan alumni STIKES Dirgahayu Samarinda sebagai terapis, kemudian seorang admin dengan latar belakang pendidikan SMK jurusan akuntasi. Ibu pengasuh berjumlah empat orang yang dibagi menjadi dua tugas jaga/ shift. Tugas jaga pagi mulai pukul 06.3015.00 dan tugas jaga siang 09.30-15.00 WITA. Mahasiswa magang berjumlah empat yaitu dua orang mahasiswa tingkat 1 dan dua orang mahasiswa tingkat

Mahasiswa magang dijadwalkan tiap hari Sabtu dan Minggu untuk memberikan pengalaman kerja dan keterampilan khusus pijat bayi.

Unit TPA buka dari hari Senin sampai Jumat mulai pukul 07.00-18.00 (10 jam pengasuhan). Unit Baby SPA buka Senin sampai Kamis pukul 10.00-18.00 dan Sabtu-Minggu pukul 09.00-18.00 WITA. Homecare service juga disediakan bagi orang tua yang menginginkan pijat bayi di rumah. Admin mengelola promosi dan layanan umum bagi pelanggan. Promosi menggunakan media brosur yang disebarkan secara langsung kepada masyarakat dan melalui media social Facebook dan Instagram "griyadirgahayu". Pemesanan jadwal terapi dan informasi 
tentang TPA dilakukan menggunakan nomor ponsel Griya Sehat melalui telpon, pesan singkat dan Whatsapp.

Jasa yang ditawarkan oleh Griya sehat bayi dan balita adalah treatment treatment yang telah terbukti secara ilmiah dan masih mempunyai banyak peluang untuk dikembangkan melalui penelitianpenelitian mengenai pertumbuhan dan perkembangan bayi dan balita. Inovasi yang diterapkan pada produk jasa ini adalah teknik massage yang digunakan menggabungkan beberapa teknik sehingga dapat memberikan manfaat tambahan yaitu meningkatkan nafsu makan pada bayi dan balita, selain itu juga menerapkan homecare (perawatan di rumah) khusus untuk pijat bayi, pemeriksaan DDST, pemeriksaan berat badan dan tinggi badan serta konsultasi pertumbuhan perkembangan bayi/ balita bagi orang tua

\section{HASIL DAN PEMBAHASAN}

Sumber dana dari hibah Kemenristek Dikti diperkuat dengan dukungan dari institusi yaitu berupa dana untuk penyewaan tempat usaha karena lokasi dalam kampus belum memungkinkan untuk menjalankan usaha ini.

Taman penitipan anak memberikan wahana bagi orang tua untuk meninggalkan anak dengan aman selama bekerja. Pelayanan yang diberikan melalui online CCTV yang terhubung dengan jaringan internet dinilai sangat memuaskan oleh orang tua dan menjadi keunggulan TPA Griya Sehat Bayi dan Balita milik STIKES Dirgahayu Samarinda. Komunikasi antara pengalola dengan orang tua dilakukan secara rutin agar pertumbuhan dan perkembangan anak selama dititipkan pada periode tertentu dapat dilaporkan kepada orang tua. Selain itu, kebutuhan khusus anak dikomunikasikan melalui grup di aplikasi whatsapp telah dinilai memudahkan orang tua terhubung dengan ibu pengasuh.
Penilaian orang tua terhadap pengasuhan di unit TPA $80 \%$ menyatakan puas dan $20 \%$ menyatakan sangat puas. Penyambutan, keramahan, kecepatan respon dan kelengkapan fasilitas baby SPA dinilai sangat memuaskan. Kejelasan jenis pelayanan, kebersihan dan kenyamanan dinilai memuaskan oleh pelanggan baby SPA. Wawancara dengan orang tua yang membawa kembali bayinya untuk SPA mengatakan keluhan sulit tidur dan tidur tidak nyenyak sudah berkurang. Anak lebih pulas tidurnya setelah dilakukan SPA. Hal ini sesuai dengan beberapa hasil penelitian. Massage (pijat) dan solus per aqua (SPA) merupakan metode untuk merangsang pertumbuhan dan perkembangan yang optimal pada bayi dan balita. Beberapa penelitian tentang manfaat massage yaitu penelitian oleh Nursari, Soetjiningsih, \& Prawirohartono, (2011) menemukan bahwa terdapat peningkatan berat badan yang signifikan pada bayi baru lahir yang dilakukan massage; penelitian oleh Gurol \& Polat (2012) menemukan bahwa massage efektif meningkatkan kasih sayang antara bayi dan ibunya; penelitian Triandari (2011) menemukan bahwa massage meningkatkan kemampuan mengangkat kepala posisi tengkurap pada bayi usia 3 4 bulan; penelitian oleh Kusumastuti, Tamtomo, \& Salimo (2016) menemukan bahwa massage efektif meningkatkan kualitas tidur, perkembangan motorik halus dan motorik kasar. Penelitian - penelitian tentang manfaat SPA diantaranya penelitian Widodo \& Afrina (2013) yang menemukan bahwa SPA bayi efektif meningkatkan lamanya tidur bayi; penelitian Daniati (2012) menemukan bahwa terdapat perbedaan yang signifikan antara kelompok yang diberikan SPA dan yang tidak terhadap kemampuan motorik kasar bayi; penelitian oleh Aryunani \& Wilianarti (2016) menemukan bahwa terdapat pengaruh yang signifikan stimulus swimming and massage terhadap 
perkembangan motorik optimal bayi usia 6 -12 bulan.

Terapis yang merupakan perawat dengan latar belakang pendidikan diploma III Keperawatan memiliki dasar ilmu kesehatan dan keperawatan anak menjadi modal utama. Selain itu, untuk meningkatkan keterampilan khusus SPA, terapis dilatih khusus oleh dua pelatih yang tersertifikasi Baby SPA dan pernah melakukan penelitian dengan topik Pijat Bayi. Selama masa training, terapis diuji dan dikoreksi oleh pelatih. Ibu pengasuh pada unit TPA direkrut secara khusus dengan kualifikasi tertentu untuk memenuhi kebutuhan pengasuhan. lbu pengasuh diberikan pelatihan Cara Komunikasi pada Anak, Penanganan Anak Tantrum dan Pertolongan Kegawatdaruratan pada Anak. Pelatihan diberikan oleh terapis Okupasi, terapis wicara dan perawat.

Daya tampung TPA adalah untuk 10 orang anak. Hasil evaluasi periode bulan Maret sampai dengan Juli jumlah anak yang dititip dengan mengambil paket bulanan (dititip setiap hari) sebanyak enam (6) orang. Hal ini berarti target penitipan anak baru mencapai $60 \%$. Anak yang dititip dengan paket harian adalah sebanyak total 10 orang dengan lama periode menitip antara 1-15 hari. Pelayanan baby SPA baru mencapai target pelanggan sebanyak $50 \%$ pada jenis treatment baby spa. Jenis pelayanan pemeriksaan tumbang belum dimanfaatkan pelanggan.

Hambatan dalam pengelolaan usaha ini adalah pada persiapan ruangan SPA karena secara teknis sarana dan prasarana yang dibutuhkan harus disiapkan secara rinci seperti ukuran, bahan dan model. Hambatan selanjutnya adalah kegiatan promosi yang masih dirasa kurang optimal berhubungan dengan keterbatasan waktu pengelola. Promosi dilakukan dengan memberikan potongan harga (discount) pada pelanggan SPA belum cukup efektif untuk menarik pelanggan baru. Hal ini mungkin karena masyarakat belum seluruhnya memahami manfaat pijat bayi dan SPA bagi pertumbuhan anak-anak. Jenis pelayanan pengukuran pertumbuhan dan pemantauan perkembangan juga masih minim pelanggan. Hal ini mungkin disebabkan karena kurangnya materi promosi pengukuran tumbang dan belum familiar di masyarakat. Lokasi unit usaha yang belum menyatu dengan lingkungan kampus STIKES Dirgahayu Samarinda dan RS Dirgahayu. Lokasi yang strategis akan membantu sosialisasi secara lebih mudah dan lebih cepat diakses oleh calon konsumen.

\section{KESIMPULAN}

Usaha Griya Sehat Bayi dan Balita milik STIKES Dirgahayu menjadi jenis usaha pelopor pelayanan terintegrasi penitipan anak, pemantauan tumbuh kembang dan baby SPA. Unit usaha ini memberikan peluang pekerjaan pada alumni untuk menjadi terapis, mahasiswa mengikuti program magang dan memberi peluang kerja pada ibu pengasuh. Orang tua anak menilai puas dengan pelayanan TPA dan sangat puas dengan adanya fasilitas CCTV online. Unit baby SPA memberikan pelayanan dari segi penyambutan, keramahan, kecepatan respon dan kelengkapan fasilitas dinilai sangat memuaskan. Kejelasan jenis pelayanan, kebersihan dan kenyamanan dinilai memuaskan oleh pelanggan. Saran dalam pengembangan usaha ini adalah mengintegrasikan lokasi unit usaha untuk berada di dalam area kampus dan RS Dirgahayu agar pengelola lebih mudah melakukan kontrol dan memudahkan promosi. Penguatan modal usaha dikembangkan untuk melengkapi fasilitas yang lebih nyaman dan menarik pelanggan serta untuk kegiatan promosi seperti iklan di surat kabar atau penyebaran promosi lewat SMS.

\section{UCAPAN TERIMA KASIH}


1. Direktorat Riset dan Pengabdian kepada Masyarakat Kemenristek Dikti Rl atas pemberian dana hibah dengan skema Program Pengembangan Usaha Produk Intelektual Kampus (PPUPIK) dalam Kontrak Pengabdian kepada Masyarakat tahun anggaran 2018 nomor: 580/ KONTRAKPENGABDIAN/K11/ KM/ 2018 Tanggal 22 Februari 2018 dengan nilai kontrak Rp. 150.000.000 (Seratus Lima Puluh Juta Rupiah).

$$
\text { 2. Ketua Yayasan Setia Budi }
$$

Samarinda atas dukungan dalam perintisan usaha

\section{Ketua STIKES Dirgahayu}

Samarinda atas arahan dan kontribusi dana institusi untuk usaha ini

\section{DAFTAR PUSTAKA}

Aryunani, \& Wilianarti, P. F. (2016). Pengaruh Stimulasi Dengan Metode Swimming And Massage (MSM) Terhadap Perkembangan Motorik Optimal Bayi 6 - 12 Bulan. Health Sciences Journal.

Daniati, S. A. (2012). Pengaruh Baby Solus Per Aqua (SPA) Terhadap Kemampuan Motorik Kasar Bayi Usia 6 - 9 Bulan. Retrieved May 25, 2017, From http://eprints.ums.ac.id:

http://eprints.ums.ac.id/21937/

Gurol, A., \& Polat, S. (2012). The Effects Baby Massage On Attachment Between Mother And Their Infants. Asian Nursing Research , 35 - 41.

Kusumastuti, N. A., Tamtomo, D., \& Salimo, H. (2016). Effect Of Massage On Sleep Quality And Motor Development In Infant Aged 3 - 6 Months. Journal of Maternal and Child Health , 161 - 169.

Nursari, D., Soetjiningsih, \& Prawirohartono. (2011). Effect Of Massage
Stimulation On Weight Gain In Full Term Infants. Paediatrica Indonesian Journal, 202 - 206.

Triandari, R. A. (2011, May 18).

Pengaruh Pijat Bayi Terhadap

Kemampuan Mengangkat Kepala

Pada Posisi Tengkurap Bayi Usia 3 - 4

Bulan. Retrieved May 25, 2017, from

http://eprints.ums.ac.id:

http://eprints.ums.ac.id/12454/

Widodo, A., \& Afrina, D.

N. (2013, Juny 19).

Efektivitas Baby Spa Terhadap Lamanya

Tidur Bayi Usia 3 - 4 Bulan. Retrieved May 25, 2017, from publikasiilmiah.ums.ac.id: https://publikasiilmiah.ums.ac.id/handle/116 17/

3316. 